\title{
Studying the Calibration Compact Lamps as a Working Standards
}

\author{
E. M. El-Moghazy ${ }^{1}$, F.M. EL-Sharkawy ${ }^{2}$
}

Photometry department, National Instituted of Standard, Giza, Egypt

\begin{abstract}
:
Working standards for compact lamps is very important to some inspection organizations in Egypt. We prepare the working standard lamp of high power compact lamp . These lamps provide the realization of luminous flux scale in the photometry laboratory in national institute for standard (NIS). We choose three types of lamps in our study. The lamp types are compact florescent lamp at nominal watt (WL1) 85watt, (WL2) at nominal Watt 105 Watt with ballast and (WL3) at nominal Watt 105watt without ballast. The spectral power distributions of all the standard lamps and test lamps are measured. The results of experimentally obtained values of luminous flux of each lamp type at the calibration values of supply voltage at 220 volts are illustrated.
\end{abstract}

Keywords: luminous flux, compact lamps, the spectral power distributions \& uncertainties.

\section{Introduction:}

Most the studies for the CFL ate either Ultraviolet radiation (UVR) is hazardous to patients with photosensitive skin disorders or sources of great electromagnetic fields. In 2013 Measuring Luminous Flux of Compact Fluorescent Lamps (CFLs) are done the purpose of this study was to compare the CFL's luminous flux measurement with the measured data provided by another test laboratory. To this end, the lamp was specified as $7 \mathrm{~W}$ at 230 $\mathrm{V} / 50 \mathrm{~Hz}$ at room temperature, and the measurement conditions were stipulated with the lamp functioning at $25^{\circ} \mathrm{C}$ ambient temperature.

Luminous flux it is important parameter for some inspection organizations in Egypt. They sent an order to national institute for standards (NIS) photometric department to provide them with luminous flux working standards for compact lamps. Also for industrial laboratories like to like comparisons are safer and preferred to avoid corrections such as spectral mismatch factor and self absorption. Due to unavailability of standard quality for such lamps a search for commercially available lamps for this purpose is under way.Three lamps areavailable; each group consists of 10 lamps of the same type. The lamp types are compact florescent lamp at nominal watt (WL1) 85watt, (WL2) at nominal Watt 105 Watt with ballast and (WL3) at nominal Watt 105watt without ballast. Lamps operation and seasoning; It is obvious that the investigated lamps are sensitive to burning position. The three types of lamps are always operated at the base-up vertical position. The lamps should be operated on AC power at supply voltage $220 \mathrm{~V}$ and the ballast will be selected such that the current must be meeting the specification issued by IEC document.(1,2,3) As the luminous flux of the lamps changes significantly with ambient temperature, which must be controlled within $25 \mathrm{oC} \pm 1$ oCbefore starting the measurements and the lamps should be stabilized for $15 \mathrm{~min}$. with integrating sphere open. The lamps should be seasoned until the photometric and electric characteristics remain constant. In the present work according to IES guide. $(4,5)$ The compact lamps must be seasoned for 100 operating hours and should be cycled 11 hours on and one hour off. After the stabilization of the lamps the measurement of the aging characteristic must be performed for each lamp.

\section{2- Experimental Set-up 2-1-Equipments for Calibration:}

Fig. (1) Shows the geometry of the NIS $2.5 \mathrm{~m}$ integrating sphere in the routine calibration setting. The integrating sphere is equipped with $\mathrm{V}(\lambda)-$ corrected filter, cosine -corrected detector, a baffle screen, auxiliary lamp, a temperature sensor and spectroadiometer. The $\mathrm{V}(\lambda)$ corrected detector is LMT standard photometers equipped with opal glass diffuser. The detector has a linearity response with range $16-28 \mathrm{nA} / \mathrm{lx}$, based on these characteristics the 
total luminous flux from $0.01 \mathrm{~lm}$ to $106 \mathrm{~lm}$ can be measured in direct substitution with total luminous flux standard lamps of any wattage. The sphere wall is coated with barium sulfate paint with diffuse reflectance approximately 0.97 in the visible region. The spectral throughput of the sphere is obtained by measuring the relative spectral irradiance of a tungsten lamp operated inside and outside the sphere with the spectroradiometer.

The integrating sphere is also equipped with an auxiliary lamp (100 watt tungsten) on the sphere wall to measure the self absorption effects of a lamp in the sphere. The room temperature of the photometry laboratory is controlled to be about 24oC. A temperature sensor is mounted to measure the air temperature of the area inside the sphere. During lamp operation the ambient temperature in the sphere is approximately 25 oC.(6)

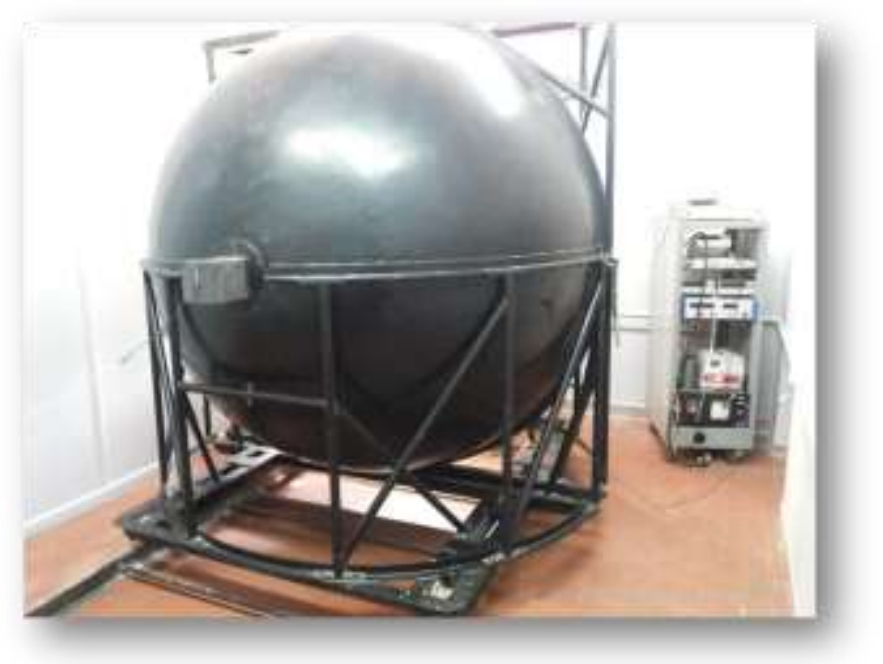

Figure1: NIS $2.5 \mathrm{~m}$ integrating sphere set up for calibrations.

\section{2-Electrical facility:}

The electrical circuit for compactlamp measurement is shown in Fig 2. The lamp is mounted in the base up position. The impedance of the ballast and the supply voltage are adjusted so that the lamp current equals the specified value. During photometric measurements the supply voltage V1, the lamp current $\mathrm{AL}$, the lamp voltage $\mathrm{V}_{\mathrm{L}}$ and the lamp power $\mathrm{W}_{\mathrm{L}}$ are measured and recorded.

\section{2-3- Luminous flux standard lamps}

The results of luminous flux measurements carried out using the sphere photometer by the substitution principle

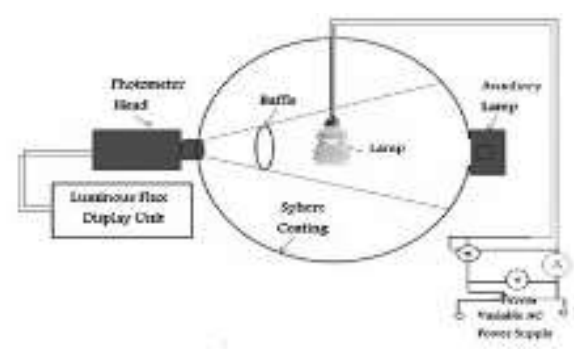

Figure 2: NIS $2.5 \mathrm{~m}$ integrating sphere set up for calibrations.

will be correct if the light source to be measured and the luminous flux standard lamp used have:(7)

- The same spectral distribution.

-The same dimensionand shape.

-The same spatiallight distribution.

If the light source to be measured and the standard lamp differ in one or more of these properties, then measurement errors may occur. The influence of different spectral distributions can be eliminated by using the mismatch correction factor which depends on full details of the spectral response of the measuring equipment (including the photometer head and sphere paint) and the spectral power distributions of the measured and the standard light source. A correction for the influence of different dimensions and shapes is possible by the use of an auxiliary lamp to determine the self absorption correction.It has been found that the most suitable standard lamp to calibrate the compact lamps is 200 Watt primary standard lamp in NIS photometry lab.

\section{3-The correction in measurements:}

For carrying the measurements of luminous flux using sphere photometer the following corrections must be carrying out.

\section{3-1-The spectral mismatch correction and its determination:}

The spectral power distributions of all the standard lamps and test lamps are measured using the spectroradiometer. The spectroradiometer is first calibrated by measuring a relative spectral radiant flux standard lamp operated in the sphere, and subsequently the test lamps are measured.

The spectral mismatch correction factor ccf of each lamp type against the 300 Watt primary standard lamp is given by

$\operatorname{ccf}\left(S_{t}, S_{s}\right)=\frac{\int_{\lambda} S_{s}(\lambda) R_{s}(\lambda) d \lambda \int_{\lambda} s_{t}(\lambda) V(\lambda) d \lambda}{\int_{\lambda} s_{s}(\lambda) V(\lambda) d \lambda \int_{\lambda} s_{t}(\lambda) R_{s}(\lambda) d \lambda}$ 
Where St $(\lambda)$ and, Ss $(\lambda)$ are the relative spectral power distribution of test and standard lamp, V $(\lambda)$ is the spectral luminous efficiency function and Rs $(\lambda)$ is the relative spectral responsivity of the sphere system.

Rs $(\lambda)$ can be obtained by measuring the relative spectral responsivity of the detector $\operatorname{Rd}(\lambda)$ and the relative spectral throughput of the integrating sphere Ts $(\lambda)$ using the following equation

$$
R_{s}(\lambda)=R_{d}(\lambda) * T_{s}(\lambda)
$$

Ts $(\lambda)$ can be obtained by measuring the relative spectral irradiance of tungsten standard lamp operating inside the sphere and outside the sphere with spectroradiometer and dividing these values. From the equation (1) the value of the ccf (St , Ss) depends on $\operatorname{St}(\lambda)$ and hence on Correlated Color Temperature (CCT) of the calibrated lamps.

\section{3-2- Self-absorption correction and its determination:}

We mean by the self-absorption correction the ratio between the quantity of the absorbed light by the lamp and baffle inside the sphere in case of standard and tested lamps. The auxiliary lamp (100 Watt) is used for the three lamp types. To determine the self-absorption correction we follow the following steps

1-The standard lamp inside the sphere is switched off and the auxiliary lamp lit. The reading of the photometer corresponding to the luminous flux of the auxiliary lamp and absorption for presence of standard lamp is measured $\mathrm{rS}$

2-The standard lamp is replaced by the lamp under test which is not switched on. The auxiliary lamp remains lit and the reading of the photometer corresponding to the luminous flux of the auxiliary lamp and absorption of the lamp under test is measured $\mathrm{rt}$ and hence the self absorption will be equal to $\mathrm{rS} / \mathrm{rt}$

\section{3-3-Correction for the sphere detector temperature:}

The responsivity of the sphere detector slightly changes with its temperature and is monitored with a temperature sensor installed in the detector package. So to avoid such error, the detector temperature must be controlled at its calibrated value.

The correction for the spatial nonuniformity of the sphere response is neglected as in this work the considered HID lamps have no reflector and hence have a regular spatial distribution.(8)

\section{4-The uncertainties budget in luminous flux measurements:}

The uncertainty factors arising in luminous flux measurement using sphere photometerare:

1-Calibration of luminous flux standard lamp: The uncertainty of luminous standard lamp is stated in calibration report issued by a laboratory in international institutes.

In this work the calibration is done in National Physical Laboratory (NPL) England.

2- Aging of the standard lamp: This uncertainty measures the rate ofluminous flux drift per hour and the interval between two calibrations

(In this work the interval is 50 hours).

3- Uncertainty due to self - absorption is $2 \sigma$ where $\sigma$ is standard deviation of the values of self absorption correction factor.

4- Repeatability of test lamps: This uncertainty calculated as two times the standard deviation $(\sigma)$ of the three measurements for each lamp.

5-uncertainty of mismatch factor correction: This uncertainty depends on the relation of ccf versus CCT and can be determined by multiplying the uncertainty of CCTof the test lamp with the slope of ccf as function of CCT for such lamp. $(9,10)$

6- Uncertainty due to the control of the electric power.

Such uncertainty can be determined by the sensitivity of variation of luminous flux and the current versus $\mathrm{Vm}$ which can be obtained by

$$
\begin{aligned}
& \mu(\Phi)=\left(\frac{\Delta \Phi}{\Phi}\right) /\left(\frac{\Delta V_{\mathrm{m}}}{V_{\mathrm{m}}}\right) \\
& \boldsymbol{\mu}(\mathbf{I})=\left(\frac{\Delta \mathrm{I}}{\mathrm{I}}\right) /\left(\frac{\Delta V_{\mathrm{m}}}{V_{\mathrm{m}}}\right)
\end{aligned}
$$

Where $\Delta \Phi$ and $\Delta \mathrm{I}$ are the variations of luminous flux and current versus the variation of $\mathrm{Vm}$ (main voltage) equals to $\Delta \mathrm{Vm} . \mu(\Phi)$ and $\mu(\mathrm{I})$ denoted by the instability factor of $\Phi$ and I versus supply voltage $\mathrm{Vm}$ which usually obtained from the relation between $\Phi$ and I against $\operatorname{Vm}$ i.e $\Phi=$ $\mathrm{f}(\mathrm{Vm})$ and $\mathrm{I}=\mathrm{f}(\mathrm{Vm})$. In all cases such relations are represented by straight lines, the slope of which equal to the values of $\mu(\Phi)$ and $\mu(\mathrm{I})$ then we have

$$
\mathrm{U}_{\mathrm{C}}(\Phi)=\boldsymbol{\kappa} \cdot \mathrm{U}_{\mathrm{C}}(\mathrm{I}) / \sqrt{3}
$$


Where UC ( $\Phi) \&$ UC (I) are uncertainties of $\Phi$ and I,

and $\kappa=\mu(\Phi) / \mu(\mathrm{I})$

, assuming that the probabilities distribution is rectangular.

\section{5- Experimental:}

According to the above mentioned item the experimental data needed to determine the uncertainty budget are:

1- The determination of $\sigma$ for self absorption correction:

The self absorption correction has been measured five times

for each lamp types accordingly the values of self absorption corrections are illustrated in table 1 .

\begin{tabular}{|l|l|l|l|}
\hline Lamps & WL1 & WL2 & WL3 \\
\hline $\begin{array}{l}\sigma \quad \text { For self } \\
\text { absorption } \\
\text { correction }\end{array}$ & 0.987 & 0.982 & 1.003 \\
\hline
\end{tabular}

Table 1: $\sigma$ for self-absorption correction for three compact lamps.

2- Performance of the three lamp types at supply voltage 220V:

The average values of the measuring $\Phi \mathrm{L}, \mathrm{WL}$, IL,VL and efficacy for the three types are represented in table 2 .

Table 2: the measuring $\Phi_{L}, W_{L}, I_{L}, V_{L}$ and efficacy for the three types.

\begin{tabular}{|l|l|l|l|}
\hline Lamps & WL1 & WL2 & WL3 \\
\hline Vm (volt) & 220 & 220 & 220 \\
\hline $\begin{array}{l}\Phi(\lambda \cup \mu \varepsilon v \sigma \\
)\end{array}$ & $\mathbf{4 5 0 0}$ & $\mathbf{5 8 0 9}$ & $\mathbf{2 4 5 9}$ \\
\hline WL(watt) & $\mathbf{7 6 . 9}$ & $\boldsymbol{8 7 . 1}$ & $\mathbf{5 4 . 2}$ \\
\hline $\begin{array}{l}\text { IL(amper) } \\
\text { VL(volt) }\end{array}$ & $\mathbf{0 . 3 6 2}$ & $\mathbf{0 . 4}$ & $\mathbf{0 . 4 4 7}$ \\
\hline efficacy & $\mathbf{5 8 . 5 2}$ & $\mathbf{6 6 . 6 9}$ & $\mathbf{2 1 9 . 3 7}$ \\
\hline
\end{tabular}

The values of flux $\Phi$ are repeatable with standard deviation $\sigma$ represented in table 3 .

Table 3: Average Value of $\sigma$ of repeatability of luminous flux for three lamp types

\begin{tabular}{|l|l|l|l|}
\hline Lamps & WL1 & WL2 & WL3 \\
\hline $\begin{array}{l}\text { Average } \\
\text { Value of } \sigma \\
\text { of } \\
\text { repeatability } \\
\text { of luminous } \\
\text { flux) }\end{array}$ & 0.898 & 0.898 & 0.588 \\
\hline
\end{tabular}

3- The experimental determination of ccf variation against CCT:

According to equation (1) to determine ccf the curve representing the spectral power distribution SPD must be obtained. We use the spectroradiometer manufactured by Ocean optics (USA) with irradiance uncertainty $\pm 4.6 \%$ to obtain the SPD for the standard and test lamps. The relation between ccf and CCT for lamp type can be obtained by spectroradiometer and hence the corresponding values of ccfusing equation (1), see figure 3 .

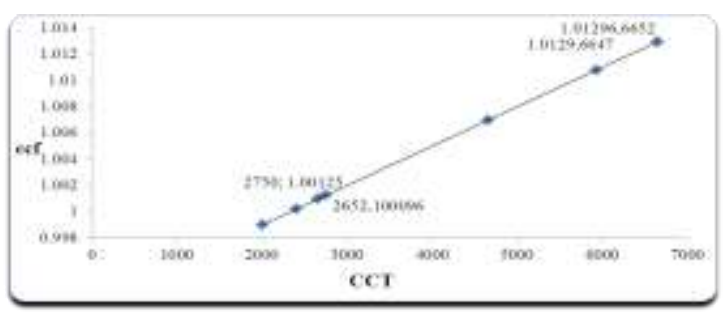

Figure. 3: The relation between ccf and CCT for WL1, WL2 and WL3 lamps.

Figure (3) represent the relations between ccf and CCT for the three lamps. Color temperature for standard lamp in this work is 2750 Kelvin and ccf $=1$. Also from the data representing SPD at $\mathrm{Vm}=220$ volt, one can obtain the value of color coordinate $(\mathrm{u} \& \mathrm{v})$ and hence using Gardner method. The uncertainty of CCT can be calculated and has been represented in table 4 . 
Table 4: The values of uncertainty of CCT for three lamp types.

\begin{tabular}{|l|l|l|l|}
\hline Parameter & WL1 & WL2 & WL3 \\
\hline CCT & 6647 (Kelvin) & $\begin{array}{l}2652 \\
\text { (Kelvin) }\end{array}$ & $\begin{array}{l}6652 \\
\text { (Kelvin) }\end{array}$ \\
\hline u & 0.236 & 0.247 & 0.249 \\
\hline v & 0.327 & 0.321 & 0.320 \\
\hline uc(u) & $4.55 \mathrm{E}-05$ & $3.87 \mathrm{E}-05$ & $7.99 \mathrm{E}-05$ \\
\hline uc(v) & $6.54 \mathrm{E}-05$ & $5.78 \mathrm{E}-05$ & $11.950 \mathrm{E}-$ \\
\hline ruv & -0.206 & -0.202 & -0.505 \\
\hline uc(CCT) & $6.5($ Kelvin) & $1.0($ Kelvin) & $\begin{array}{l}10 \\
(\text { Kelvin })\end{array}$ \\
\hline
\end{tabular}

4-The determination of the instability factor $\mu(\Phi)$ :

The variation of $\Phi$ and I versus $V m$ has been determined experimentally for the three lamp types. Figures $4(\mathrm{a}, \mathrm{b}$ and $\mathrm{c})$ represent such variations from which the average values of $\kappa$ for the three lamp types are represented in table 5.

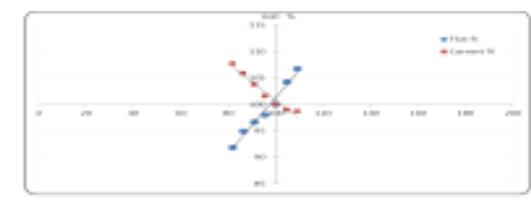

Figure. 4-a: Percentage variation of flux and current with $\mathrm{V}_{\mathrm{m}}$ for WL1 lamp.

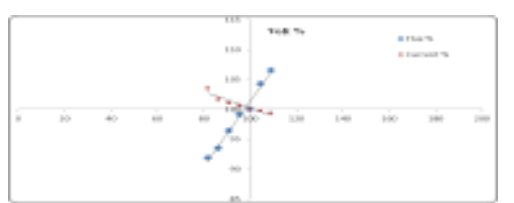

Figure. 4-b: Percentage variation of flux and current with $\mathrm{V}_{\mathrm{m}}$ for WL2 lamp.

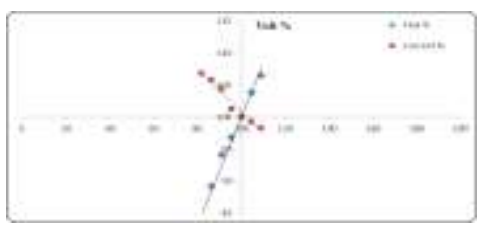

Figure. 4-c: Percentage Variation of flux and current with $\mathrm{V}_{\mathrm{m}}$ for WL3 lamp.

\begin{tabular}{|l|l|l|}
\hline Uncertainty factor & $\begin{array}{l}\text { Type A } \\
\%\end{array}$ & $\begin{array}{l}\text { Type B } \\
\%\end{array}$ \\
\hline $\begin{array}{l}\text { Calibration of luminous } \\
\text { flux standard lamp }\end{array}$ & 0.7 \\
\hline $\begin{array}{l}\text { Aging of the standard } \\
\text { lamp }\end{array}$ & 0.5 \\
\hline Self absorption correction & 0.0003 & 0.4929 \\
\hline $\begin{array}{l}\text { Spectral mismatch } \\
\text { correction }\end{array}$ & 0.89 & \\
\hline Repeatability of test lamp & 0.01 & \\
\hline $\begin{array}{l}\text { Control of the electric } \\
\text { power }\end{array}$ & $1.33 \pm$ \\
\hline $\begin{array}{l}\text { Expand uncertainty of test } \\
\text { lamp }\end{array}$ & \\
\hline
\end{tabular}

Table 5: the average value of $\kappa$ for three lamps.

\begin{tabular}{|l|l|l|}
\hline ncertainty factor & $\begin{array}{l}\text { Type A } \\
\%\end{array}$ & $\begin{array}{l}\text { Type B } \\
\%\end{array}$ \\
\hline $\begin{array}{l}\text { Calibration of luminous } \\
\text { flux standard lamp }\end{array}$ & 0.7 \\
\hline $\begin{array}{l}\text { Aging of the standard } \\
\text { lamp }\end{array}$ & 0.5 \\
\hline Self absorption correction & 0.0001 & 0.295 \\
\hline $\begin{array}{l}\text { Spectral mismatch } \\
\text { correction }\end{array}$ & 0.59 & \\
\hline Repeatability of test lamp & 0.0003 & \\
\hline $\begin{array}{l}\text { Control of the electric } \\
\text { power }\end{array}$ & $1.44 \pm$ \\
\hline $\begin{array}{l}\text { Expand uncertainty of test } \\
\text { lamp }\end{array}$
\end{tabular}

\section{6-The results of calibration and conclusion:}

As results of the experimental work and the attributed calibrations the uncertainty budget for 
luminous flux calibration for the three lamp types are illustrated in tables 6,7 and 8 .

Table 6 : Uncertainty budget for luminous flux of WL1 lamp (the confidence level is $95 \%$ so $\mathrm{k}=2$ ).

Table 7 : Uncertainty budget for luminous flux of WL2 lamp (the confidence level is $95 \%$ so $\mathrm{k}=2$ ).

\begin{tabular}{|l|l|l|}
\hline Uncertainty factor & $\begin{array}{l}\text { Type A } \\
\%\end{array}$ & $\begin{array}{l}\text { Type B } \\
\%\end{array}$ \\
\hline $\begin{array}{l}\text { Calibration of luminous } \\
\text { flux standard lamp }\end{array}$ & 0.7 \\
\hline $\begin{array}{l}\text { Aging of the standard } \\
\text { lamp }\end{array}$ & 0.5 \\
\hline Self absorption correction & 0.0007 & 0.191 \\
\hline $\begin{array}{l}\text { Spectral mismatch } \\
\text { correction }\end{array}$ & 0.89 & \\
\hline Repeatability of test lamp & 0.0002 & \\
\hline $\begin{array}{l}\text { Control of the electric } \\
\text { power }\end{array}$ & $1.25 \pm$ \\
\hline $\begin{array}{l}\text { Expand uncertainty of test } \\
\text { lamp }\end{array}$ & \\
\hline
\end{tabular}

Table 8 : Uncertainty budget for luminous flux of WL3 lamp (the confidence level is $95 \%$ so $\mathrm{k}=2$ ).

Notes: UC (I) accordingly the calibration certificate of the dc power supply is $\pm 0.002 \%$.

\section{7-Conclusions:}

For the first time in Egypt we prepare the working standard lamp of high power compact lamp. These lamps provide the realization of luminous flux scale in the photometry laboratory in national institute for standard (NIS) and also inspection organization and industrial laboratories.

The results of experimentally obtained values of luminous flux of each lamp at the calibration values of supply voltage are represent in tables $6,7,8$. All values are agreed with the IEC publications.

- We have found that for the three lamp types the lamps having uncertainty are $\pm 1.33 \%$ for WL1, $\pm 1.44 \%$ for WL2 and $\pm 1.25 \%$ for WL3 lamps.

\section{References}

1. ("Using International Electrotechnical Commission (IEC) 60188 High-pressure mercury vapor lamps / Performance specification," 2001-2005).

2. ("Using International Electrotechnical Commission (IEC) 1167 Metal halide lamps," 1992-2008)

3. ("Using International Electrotechnical Commission (IEC) 662 High-pressure sodium lamps, "1995)

4. (" Using Journal of illuminating engineering society (IES) Guide to Lamp Seasoning," 1984)

5. (" Using Journal of illuminating engineering society (IES) approved method for the electrical and photometric measurements of high intensity discharge lamps," 1989)

6. ( Ohno, July 1997), NIST Special Publication 250-37,:photometric calibrations

7. ("Using CIE Pub., No. 84 The measurement of luminous flux," 1989)

8. (Casimer, 1994). Handbook of applied photometry.

9. (Gardner, 2000), Metrologia, No.(37)

10. (Gardner, 2006), Metrologia, No (43),"

11.(El-sayed, 1992), M.sc thesis "Studies on some physical parameters of commercially available fluorescent lamps in Egypt", faculty of science, Cairo University 